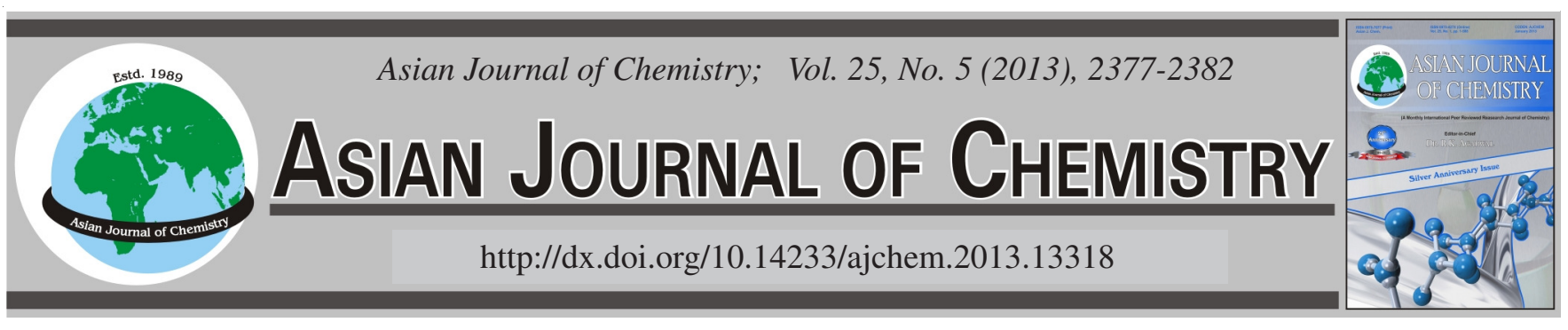

\title{
Synthesis and Theoretical Studies of 1,3,3,5,5-Pentachloro- 1-mono-(2-amidopyridin)cyclotriphosphazene
}

\author{
SAFAA A. AHMED
}

Department of Chemistry, College of Education Samarra, University of Tikrit, Tikrit-43001, Iraq

Corresponding author: E-mail: drsafaa1954@gmail.com

(Received: 23 December 2011;

Accepted: 5 November 2012)

AJC-12363

1,3,3,5,5-Pentachloro-1-mono(2-amidopyridine)cyclotriphosphazene was prepared from hexachlorocyclotriphosphazene and 2-amino pyridine in acetone. The structure of the white crystals of the prepared compound was elucidated by the X-ray diffraction and supported by the FTIR and ${ }^{1} \mathrm{H},{ }^{13} \mathrm{C},{ }^{31} \mathrm{P}$ NMR spectroscopy. Since the X-ray diffraction is not accurate in detecting the position of the hydrogen atoms, Density functional theory (B3LYP) was used to study the structure and the spectroscopic properties of the compound and its tautomers that belong to the hydrogen tautomerism. Calculations have shown that the isomer in which the hydrogen attached to the nitrogen atom of the amido nitrogen that attached to the pyridine ring has the lowest energy and that comes in accordance with ${ }^{1} \mathrm{H} N \mathrm{NR}$ and FTIR spectroscopy. Potential energy curve with calculated activation energy is reported.

Key Words: Triphosphazene, Cyclotriphosphazine, DFT, Tautomerism, Potential energy curve.

\section{INTRODUCTION}

Hexachlorocyclotriphosphazene reacts with amino derivatives in different moles ratio to form geminal and nongeminal amido phosphazene ${ }^{1,2}$. In recent years, phosphazene have attracted considerable attention because they can be tailored to possess a wide variety of physical and chemical properties by changing the side groups ${ }^{3}$. The reactions of hexachloro cyclo triphosphazene, $\left(\mathrm{N}_{3} \mathrm{P}_{3} \mathrm{Cl}_{6}\right)$, with mono, di, tri and tetra-functional amines have been extensively studied ${ }^{4-7}$ and especially large difunctional diamines were reported for a potential value in cancer chemotherapy as selective carriers for delivering anticancer drugs to malignant target cells ${ }^{8,9}$. Within the context of biological and pharmacological properties of some amido- and amino phosphazenes, nucleophilic substitutions (ammonolysis and aminolysis) belong to the two main reaction types. In the course of these reactions, a lone electron pair of the reagent nitrogen atom attacks a phosphorus atom of the phosphazene ring and amido- or amino-cyclotriphosphazene derivatives are formed under release of $\mathrm{HCl}^{10,11}$. The result of the reaction of phosphazene derivative with nucleophile reagent strongly depends on reaction conditions whereas a series of various substitution derivatives can be formed ${ }^{12-18}$. The reactions of $\mathrm{N}_{3} \mathrm{P}_{3} \mathrm{Cl}_{6}$ with aromatic primary amines (aniline, $p$-toluidine and $p$-anisidine) as a model systems for the phosphazene have shown that the second stage of chlorine replacement in methyl cyanide $(\mathrm{MeCN})$ proceeds by a bimolecular mechanism ${ }^{19}$. This result implies that the products formed are presumably the non-geminal bis-(amino) derivatives. In contrast to the previous report of a predominantly geminal mode of substitution established for aniline in benzene $e^{20,21}$.

In this study, density functional method (DFT) was used to study the tuotomers of the prepared compound. The potential energy curve, spectroscopic and thermodynamic properties are calculated and compared with the experimental results.

\section{EXPERIMENTAL}

Synthesis procedure and sample preparation were performed under dry nitrogen atmosphere. Pure hexachloro cyclotriphosphazene (cross organic) was obtained from subsequent sublimation in vacuum at $60{ }^{\circ} \mathrm{C}$. The purity was checked by ${ }^{31} \mathrm{P}$ NMR spectroscopy. 2-Aminopyridine was taken from (Aldrich), triethylamine $\left(\mathrm{Et}_{3} \mathrm{~N}\right)$ was purified according to ${ }^{22}$ and distilled before use.

${ }^{31} \mathrm{P}$ NMR spectra was recorded on a $500 \mathrm{MHz}$ BRUKERTT-AVANCE spectrometer and was referenced to $\mathrm{H}_{3} \mathrm{PO}_{4} 85 \%$ (external standard). The sample was dissolved in deuterated aceton. FT-IR spectra was measured by 2000 Perkin Elmer in $\mathrm{KBr}$ disk containing 1.2-1.7 $\mathrm{mg}$ of the sample and $100 \mathrm{mg}$ $\mathrm{KBr}$. The melting point measurment was by using Gallen Kamp apparatus. 


\begin{tabular}{|c|c|c|c|c|c|c|c|c|c|}
\hline \multicolumn{10}{|c|}{$\begin{array}{c}\text { TABLE-1 } \\
{ }^{31} \mathrm{P},{ }^{1} \mathrm{H},{ }^{13} \mathrm{C} \text { NMR SPECTRA FOR THE PREPARED COMPOUND }\end{array}$} \\
\hline Compound & ${ }^{31} \mathrm{P}(\mathrm{d})$ & $-d$ & JP-P(d) HZ & ${ }^{31} \mathrm{P}(\mathrm{t})$ & $-t$ & JP-P (t) HZ & ${ }^{13} \mathrm{C}$ & $1 \mathrm{H} \mathrm{NH}$ & JP-P HZ \\
\hline \multirow{7}{*}{$\begin{array}{l}\mathrm{P}_{3} \mathrm{~N}_{3} \mathrm{Cl}_{5} \\
(2-\mathrm{AP})\end{array}$} & 21.87 & 21.76 & 41.88 & 6.87 & & & & 1.72 & 40.89 \\
\hline & 21.66 & & & 6.67 & 6.66 & 45.98 & & & \\
\hline & & & & & & & 120.47 & & 45.33 \\
\hline & & & & & & & 122.12 & & \\
\hline & & & & & & & 127.29 & & \\
\hline & & & & & & & 129.23 & & \\
\hline & & & & & & & 141.25 & & \\
\hline
\end{tabular}

Hexachlorocyclo-tri-phosphazene $(0.5 \mathrm{~g}, 0.07 \mathrm{~mol})$ was reacted with 2-aminopyridine $(0.13 \mathrm{~g}, 0.07 \mathrm{~mol})$ and triethylamine $(0.14 \mathrm{~g}, 0.07 \mathrm{~mol})$ in acetone at $-80^{\circ} \mathrm{C}$ in mole ratio $1: 1$ in liquid nitrogen bath, however this reaction was carried out in anhydrous condition for more than $5 \mathrm{~h}$. The triethylammonium chloride was filtered off under nitrogen air, washed with dried acetone and the solvent reduced to the minimum and $10 \mathrm{~mL}$ dried acetone was added. The product yield of 1,3,3,5,5-penta chloro-1-mono-(2-amidopyridine)cyclotriphosphazene after deep freezing crystallization was about 60-66 \%, melting point $182{ }^{\circ} \mathrm{C}$. Crystals suitable for X-ray diffraction studies were obtained after two months of deep freezing uncrystallization and by nitrogen air dried.<smiles>ClP1(Cl)=NP(Cl)(Cl)=NP(Cl)(Cl)=N1</smiles><smiles>Nc1ccccn1</smiles>
$\underset{-80^{\circ} \mathrm{C} / \mathrm{Acetone}}{\stackrel{\mathrm{ET}}{3} \mathrm{NHCl}}$

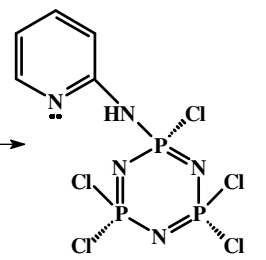

Computational methods: The structure of 1,3,3,5,5pentachloro-1-mono-(2-amidopyridine)cyclotriphosphazene and its tautomers structures were modelled according to the structure proposed by X-ray diffraction ${ }^{23}$. The optimized molecular sturctures, relative stability and vibrational frequencies were investigated by using ab initio density functional theory (B3LYP), with basis sets $6-311 \mathrm{G}++(\mathrm{d}, \mathrm{p})$. In the ground state (GS), the optimized structures have no imaginary frequencies, meanwhile, in the transition state (TS), only one imaginary frequency is observed. The harmonic frequencies and theoretical infrared and Raman spectra were computed and compared to the experimental data. All of the calculations were done by using Gaussian $03 \mathrm{~W}$ software ${ }^{24}$.

\section{RESULTS AND DISCUSSION}

The FT-IR spectra for the prepared compound, $\mathrm{P}_{3} \mathrm{~N}_{3} \mathrm{Cl}_{5}$, was compared with the reactant, 2-aminopyridine. The frequencies of the N-H stretching were 3411 and $3441 \mathrm{~cm}^{-1}$ respectively. Two frequencies was found in the spectra of $\mathrm{P}_{3} \mathrm{~N}_{3} \mathrm{Cl}_{5}$ and not in the spectra 2-aminopyridine and that proves the compound formation. The weak signal for the $\mathrm{NH}$ vibration in the prepared compound is shifted to lower frequency by $(5-8) \mathrm{cm}^{-1}$. The decreasing of the $\mathrm{P}=\mathrm{N}$ frequency is due to the weakening of the phosphazene skeleton bond as a consequence of the chlorine replacement with $\mathrm{NH}_{2}$ moiety.

The structure of the compound was elucidated by ${ }^{1} \mathrm{H},{ }^{13} \mathrm{C}$ and ${ }^{31} \mathrm{P}$ NMR spectroscopy. There are two peaks in the ${ }^{31} \mathrm{P}$
NMR spectra with similar Jp-p values 41.88 and 45.98 (d,t) that show that the compound have one isomer. The ${ }^{1} \mathrm{H}$ and ${ }^{13} \mathrm{C}$ NMR data also confirm the structure of the compound. The aromatic $\mathrm{CH}$ for the pyridine ring appears between 120 and $141 \mathrm{ppm}$. In the ${ }^{1} \mathrm{H}$ NMR spectra, the $\mathrm{NH}$ proton is observed at $1.72 \mathrm{ppm}$, which shows according to the integral intensities that there is one position for the $\mathrm{NH}$ proton in the compound. Several references had been reported in literature regarding the amido phosphazen, such as methylamine, dimethylamine, ethylamine, piperidine ${ }^{25,26}$.

\section{Geometry optimization}

Four structures was modeled for the prepared compound as follows; GS1, in which the hydrogen atom is attached to the nitrogen atom of the pyridine ring, GS2, is the structure in which the hydrogen atom is attached to the amido group and GS3 and GS4 in which the hydrogen is attached to the ortho and meta nitrogen atoms of the triphosphazene ring respectively. In addition, three transition state structures were modeled in which the hydrogen atom is in between the GS1 and GS2, (TS1), GS2 and GS3, (TS2) and GS2 and GS4, (TS3). The optimized structures of 1,3,3,5,5-penta chloro-1-mono (2-amidopyridine) cyclo triphosphazene and its tautomers in the TSs and GSs are illustrated in Fig. 1.

Tables 2 and 3 show the optimized structural parameters at DFT level of calculation for the 1,3,3,5,5-penta chloro-1mono (2-amidopyridine) cyclo triphosphazen. Results show most of the bond parameters predicted theoretically in the GS2 are comparable to the experimental data. However, the computed $\mathrm{C}-\mathrm{H}$ and $\mathrm{N}-\mathrm{H}$ bonds are slightly longer than the experimental data. Also, the $5 \mathrm{H}-1 \mathrm{~N}-5 \mathrm{C}$ and $5 \mathrm{C}-2 \mathrm{~N}-2 \mathrm{P}$ bond angles have $2.7^{\circ}$ and $3.8^{\circ}$ difference compared to the experimental data, while the rest of the bond angles have not shown significant deviation.

When the molecule at GS1 undergoes a TS (TS1), the 5H atom is observed located between $1 \mathrm{~N}$ and $2 \mathrm{~N}$ atoms (Table-2). The $1 \mathrm{~N}-5 \mathrm{H}$ bond distance has increased by $0.305 \AA$ and the $1 \mathrm{~N}-5 \mathrm{H}$ and $2 \mathrm{~N}-5 \mathrm{H}$ bond distances are $1.318 \AA$ and $1.380 \AA$, respectively. In general, most of the bond distances in the TS1 did not changed significantly as in the GS1. Also, the 4C-5C$1 \mathrm{~N}$ and $4 \mathrm{C}-5 \mathrm{C}-2 \mathrm{~N}$ bond angles increased $6.6^{\circ}$ and $6.7^{\circ}$, respectively in the $\mathrm{TS} 1$. The computed activation energy in the TS1 is $+35.05 \mathrm{kcal} / \mathrm{mol}$ (Fig. 2) with respect to the GS1.

In the GS2, the $5 \mathrm{H}$ atom is no longer sharing between $1 \mathrm{~N}$ and $2 \mathrm{~N}$ atoms and it is observed to be bonded to $2 \mathrm{~N}$ atom. The $2 \mathrm{~N}-5 \mathrm{H}$ bond distance was observed to be shortened from 1.380 $\AA$ in the TS1 to $1.016 \AA$ in the GS2. Next, the bond angles of $4 \mathrm{C}-5 \mathrm{C}-2 \mathrm{~N}$ and $5 \mathrm{C}-1 \mathrm{~N}-1 \mathrm{C}$ are narrowed down $14.4^{\circ}$ and $4.6^{\circ}$, respectively, in the GS2. Despite these mentioned parameters, 


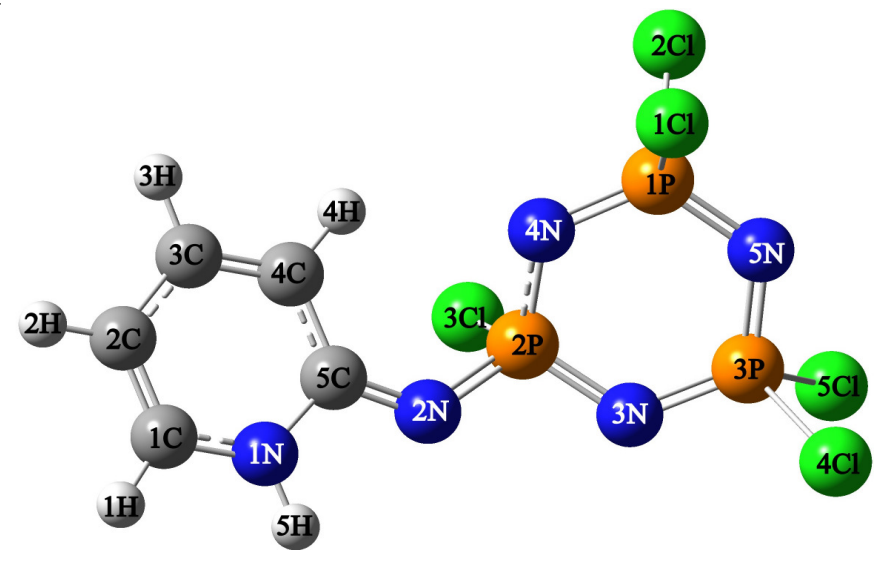

GS1
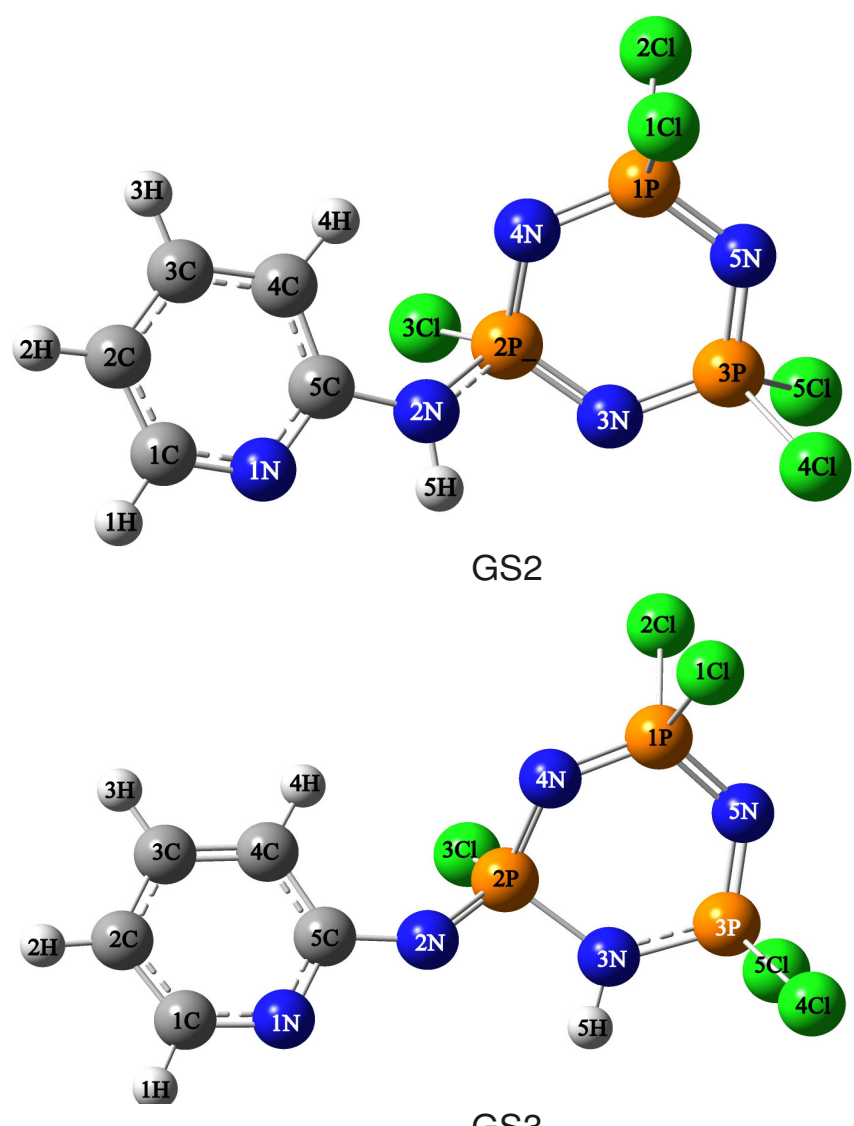

GS3

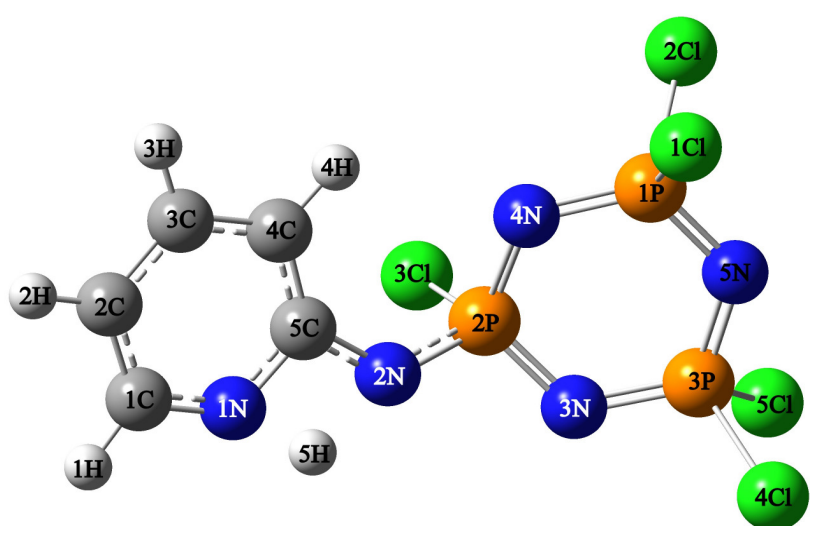

TS1
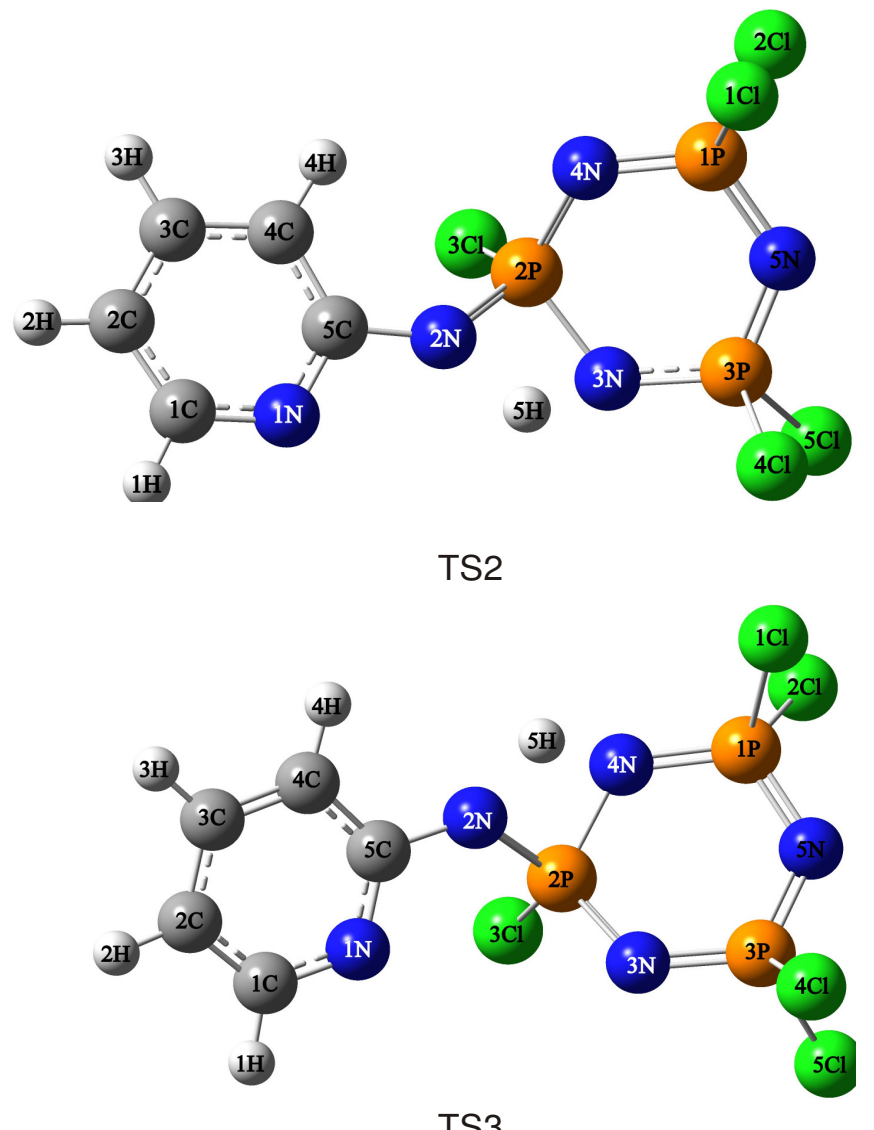

TS3

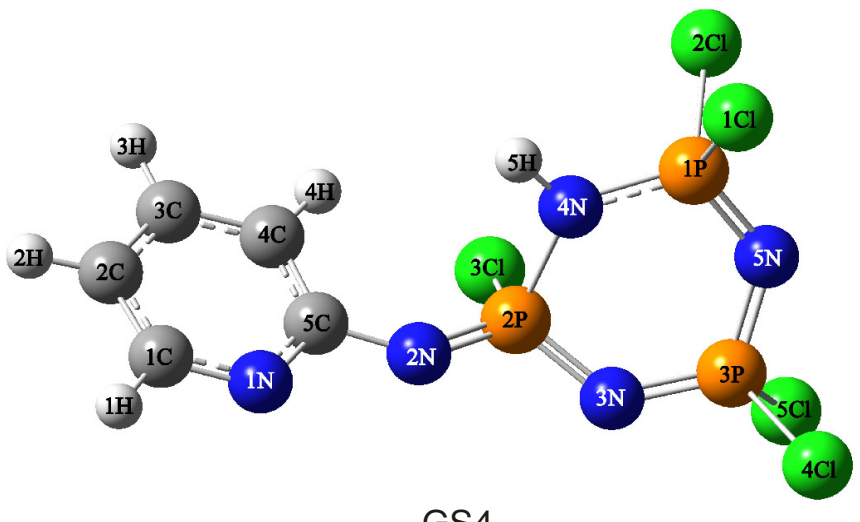

Fig. 1. Atoms numbering and structures of 1,3,3,5,5-penta chloro-1-mono (2-amidopyridine)cyclo triphosphazene and its tautomers structures in the ground state and transition state 
TABLE-2

OPTIMIZED STRUCTURAL PARAMETERS OF 1,3,3,5,5-PENTACHLORO-1-MONO(2-AMIDOPYRIDINE)

CYCLO TRIPHOSPHAZENE AND ITS TAUTOMERS STRUCTURES CALCULATED AT B3LYP/ 6-311++G(d,p) LEVEL OF THEORY AND THE EXPERIMENTAL DATA

\begin{tabular}{|c|c|c|c|c|c|c|c|c|}
\hline \multicolumn{9}{|c|}{ Bond Distance $(\AA)$} \\
\hline & GS1 & TS1 & GS2 & TS2 & GS3 & TS3 & GS4 & Exp. \\
\hline $1 \mathrm{C}-1 \mathrm{H}$ & 1.082 & 1.083 & 1.086 & 1.087 & 1.087 & 1.086 & 1.087 & 0.908 \\
\hline $2 \mathrm{C}-2 \mathrm{H}$ & 1.080 & 1.081 & 1.083 & 1.083 & 1.083 & 1.083 & 1.083 & 0.914 \\
\hline $3 \mathrm{C}-3 \mathrm{H}$ & 1.084 & 1.084 & 1.084 & 1.084 & 1.085 & 1.084 & 1.085 & 0.951 \\
\hline $4 \mathrm{C}-4 \mathrm{H}$ & 1.081 & 1.081 & 1.082 & 1.084 & 1.083 & 1.083 & 1.083 & 0.916 \\
\hline $1 \mathrm{C}-2 \mathrm{C}$ & 1.363 & 1.388 & 1.390 & 1.391 & 1.391 & 1.390 & 1.392 & 1.365 \\
\hline $1 \mathrm{C}-1 \mathrm{~N}$ & 1.360 & 1.335 & 1.336 & 1.336 & 1.335 & 1.337 & 1.334 & 1.357 \\
\hline $2 C-3 C$ & 1.418 & 1.403 & 1.394 & 1.395 & 1.394 & 1.397 & 1.393 & 1.399 \\
\hline $3 \mathrm{C}-4 \mathrm{C}$ & 1.369 & 1.390 & 1.388 & 1.386 & 1.386 & 1.386 & 1.387 & 1.371 \\
\hline $4 C-5 C$ & 1.433 & 1.397 & 1.340 & 1.407 & 1.409 & 1.405 & 1.411 & 1.421 \\
\hline $5 \mathrm{C}-1 \mathrm{~N}$ & 1.384 & 1.359 & 1.332 & 1.337 & 1.340 & 1.339 & 1.340 & 1.359 \\
\hline $5 \mathrm{C}-2 \mathrm{~N}$ & 1.313 & 1.368 & 1.413 & 1.392 & 1.386 & 1.387 & 1.384 & 1.346 \\
\hline $1 \mathrm{~N}-5 \mathrm{H}$ & 1.013 & 1.318 & - & - & - & - & - & 0.835 \\
\hline $2 \mathrm{~N}-5 \mathrm{H}$ & - & 1.380 & 1.016 & 1.416 & - & 1.391 & - & - \\
\hline $3 \mathrm{~N}-5 \mathrm{H}$ & - & - & - & 1.271 & 1.015 & - & - & - \\
\hline $2 \mathrm{P}-3 \mathrm{Cl}$ & 2.099 & 2.091 & 2.069 & 2.060 & 2.112 & 2.049 & 2.115 & 2.055 \\
\hline $2 \mathrm{P}-3 \mathrm{~N}$ & 1.611 & 1.607 & 1.605 & 1.705 & 1.749 & 1.600 & 1.602 & 1.603 \\
\hline $2 \mathrm{P}-4 \mathrm{~N}$ & 1.627 & 1.620 & 1.607 & 1.603 & 1.616 & 1.712 & 1.782 & 1.610 \\
\hline $3 N-3 P$ & 1.583 & 1.585 & 1.592 & 1.622 & 1.645 & 1.582 & 1.569 & 1.572 \\
\hline $4 \mathrm{~N}-1 \mathrm{P}$ & 1.867 & 1.620 & 1.590 & 1.585 & 1.571 & 1.618 & 1.645 & 1.571 \\
\hline $4 \mathrm{~N}-5 \mathrm{H}$ & - & - & - & - & - & 1.278 & 1.014 & - \\
\hline $1 \mathrm{P}-1 \mathrm{Cl}$ & 2.053 & 2.051 & 2.044 & 2.040 & 2.035 & 2.044 & 2.040 & 2.015 \\
\hline $1 \mathrm{P}-2 \mathrm{Cl}$ & 2.055 & 2.051 & 2.045 & 2.040 & 2.043 & 2.036 & 2.037 & 1.991 \\
\hline $1 \mathrm{P}-5 \mathrm{~N}$ & 1.597 & 1.597 & 1.597 & 1.603 & 1.616 & 1.584 & 1.564 & 1.586 \\
\hline $5 N-3 P$ & 1.601 & 1.600 & 1.597 & 1.585 & 1.563 & 1.605 & 1.616 & 1.584 \\
\hline $3 \mathrm{P}-4 \mathrm{Cl}$ & 1.049 & 2.047 & 2.042 & 2.039 & 2.037 & 2.040 & 2.035 & 2.001 \\
\hline $3 \mathrm{P}-5 \mathrm{Cl}$ & 2.052 & 2.049 & 2.043 & 2.034 & 2.033 & 2.040 & 2.039 & 1.999 \\
\hline
\end{tabular}

the rest of the bond parameters did not deviate drastically from TS1 to GS2. The predicted forward energy in the GS2 is $-38.03 \mathrm{kcal} / \mathrm{mol}$ (Fig. 2).

Subsequently, in the GS2 the molecule undergoes a TS (TS2), where the $5 \mathrm{H}$ atom is moving in between the $2 \mathrm{~N}$ and $3 \mathrm{~N}$ atoms (Table-1). The $2 \mathrm{~N}-5 \mathrm{H}$ bond distance has increased by $0.4 \AA$ in the TS 2 and became $1.416 \AA$. The $3 \mathrm{~N}-5 \mathrm{H}$ bond distance is slightly shorter than the $2 \mathrm{~N}-5 \mathrm{H}$ bond distance $(1.271$ $\AA$ ). Then, the $5 \mathrm{H}-2 \mathrm{~N}-5 \mathrm{C}$ bond angle has increased $31.8^{\circ}$ to $143.8^{\circ}$ in the TS1. In general, the rest of the bond parameters in the TS2 did not changed significantly compared to the GS1. The computed activation energy in the TS2 is $+46.19 \mathrm{kcal} /$ mol (Fig. 2), which is $11.14 \mathrm{kcal} / \mathrm{mol}$ less stable than the reaction in the TS1.

In the forward reaction of TS2 (GS3), the $5 \mathrm{H}$ atom is observed to be bonded to $3 \mathrm{~N}$ atom with a bond distance of $1.015 \AA$. Next, the bond angles of $5 \mathrm{H}-3 \mathrm{~N}-2 \mathrm{P}, 5 \mathrm{C}-2 \mathrm{~N}-2 \mathrm{P}$ and $2 \mathrm{P}-4 \mathrm{~N}-1 \mathrm{P}$ are broaden $35.9^{\circ}, 2.3^{\circ}$ and $3.0^{\circ}$, respectively, in the GS3. With exceptions of these bond parameters, the remaining bond parameters did not have significant changes from TS2 to GS3. The predicted forward energy in the GS3 is -23.54 $\mathrm{kcal} / \mathrm{mol}$ (Fig. 2), which are $14.49 \mathrm{kcal} / \mathrm{mol}$ less exothermic than GS2.

Again, the molecule GS3 the molecule undergoes a TS intermediate (TS3). The $5 \mathrm{H}$ atom is moving in between of $2 \mathrm{~N}$ and $3 \mathrm{~N}$ atoms (Table- 1 ). The $2 \mathrm{~N}-5 \mathrm{H}$ and $4 \mathrm{~N}-5 \mathrm{H}$ bond distances in then TS3 are $1.278 \AA$ and $1.391 \AA$, respectively. The $3 \mathrm{~N}$ $5 \mathrm{H}$ bond distance is slightly shorter than the $2 \mathrm{~N}-5 \mathrm{H}$ bond distance $(1.271 \AA)$. As a conclusion, all of the bond distances in the TS3 and GS3 are comparable to one another. However, due to the different conformation observed in the TS3 and GS3 (Table-1), the 5C-2N-2P, 2P-4N-1P, 5N-3P-4Cl and 5N$3 \mathrm{P}-5 \mathrm{Cl}$ bond angles are observed to be decreased in the interval of $3^{\circ}-9^{\circ}$ and $5 \mathrm{~N}-3 \mathrm{P}-3 \mathrm{~N}$ bond angle increased $4.3^{\circ}$ in the TS3. The computed activation energy in the TS3 is $+20.88 \mathrm{kcal} /$ mol (Fig. 2), which is kinetically more stable than the TS1 and TS2 by 14.17 and $25.31 \mathrm{kcal} / \mathrm{mol}$, respectively. In the forward reaction (GS4), the $5 \mathrm{H}$ atom is found bonded to $4 \mathrm{~N}$ atom with a bond distance of $1.014 \AA$ and the $5 \mathrm{H}-4 \mathrm{~N}-2 \mathrm{P}$ bond angle has increased $37.5^{\circ}$ and became $115.1^{\circ}$. Due to the conformation of molecule changed from TS3 to GS4, the bond angle of $5 \mathrm{C}-2 \mathrm{~N}-2 \mathrm{P}$ has highly broadened $10.8^{\circ}$, while the $2 \mathrm{~N}-$ $2 \mathrm{P}-3 \mathrm{Cl}, 2 \mathrm{P}-4 \mathrm{~N}-1 \mathrm{P}$ and $3 \mathrm{P}-3 \mathrm{~N}-2 \mathrm{P}$ bond angles are slightly increased $2.5^{\circ}, 2.9^{\circ}$ and $3.1^{\circ}$, respectively, in the GS4. The predicted forward energy in the GS4 is $-18.62 \mathrm{kcal} / \mathrm{mol}$, Fig. 2, which are 19.41 and $4.92 \mathrm{kcal} / \mathrm{mol}$ less exothermic than GS2 and GS3.

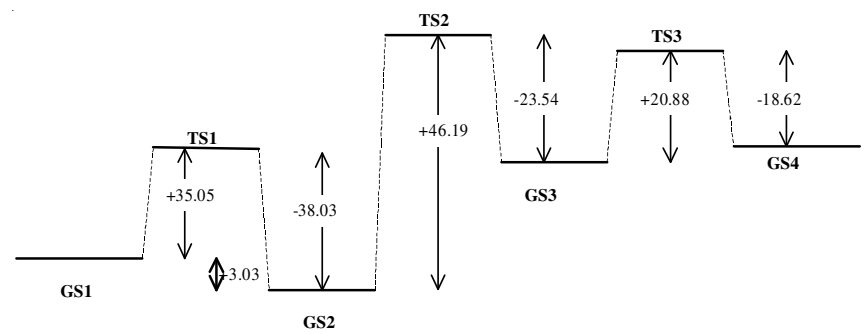

Fig. 2. Energy profile for the 1,3,3,5,5-penta chloro-1-mono (2-amidopyridine) cyclo triphosphazene and its tautomers structures 


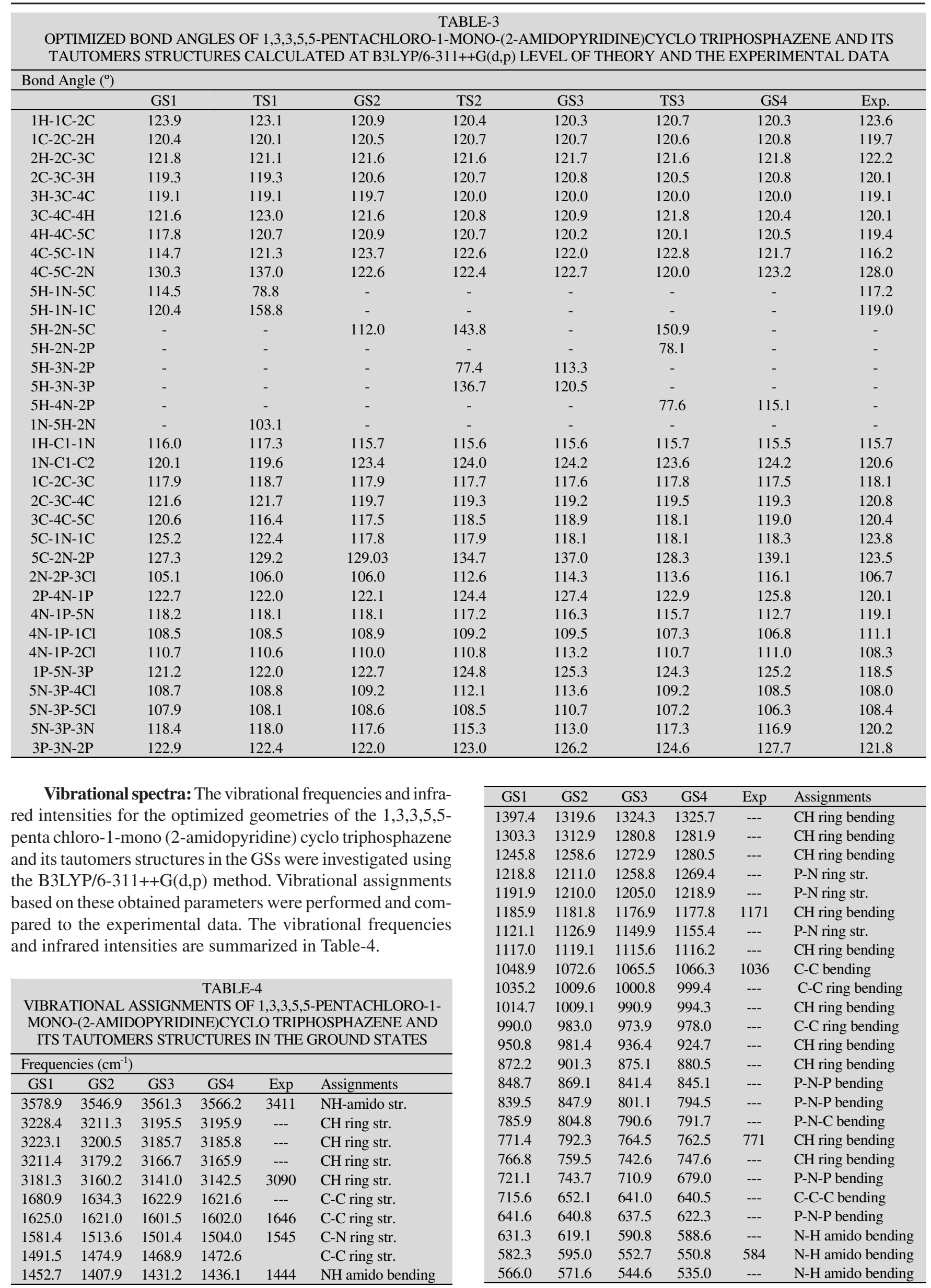




\begin{tabular}{cccccl}
\hline & & & & & \\
\hline GS1 & GS2 & GS3 & GS4 & Exp & Assignments \\
\hline 534.0 & 544.4 & 526.1 & 526.6 & --- & P-N-P bending \\
507.5 & 523.7 & 510.0 & 508.2 & --- & CH ring bending \\
499.5 & 507.4 & 482.1 & 470.9 & --- & P-N-P bending \\
496.8 & 489.4 & 471.1 & 464.9 & --- & N-H amido bending \\
468.2 & 469.7 & 444.0 & 434.8 & --- & P-N-P bending \\
392.1 & 420.0 & 419.1 & 422.8 & --- & C-C-C bending \\
373.3 & 375.9 & 374.9 & 374.2 & --- & P-N-P bending \\
340.5 & 350.6 & 336.7 & 337.8 & --- & P-N-C bending \\
331.7 & 332.7 & 334.0 & 329.6 & --- & P-N-P bending \\
329.6 & 328.9 & 319.8 & 325.2 & --- & P-N-P bending \\
319.4 & 318.6 & 318.4 & 303.9 & --- & P-N-P bending \\
317.5 & 312.1 & 307.4 & 300.0 & --- & P-N-P bending \\
288.5 & 301.8 & 284.6 & 267.6 & --- & P-N-P bending \\
271.1 & 255.8 & 246.1 & 263.6 & --- & P-N-P bending \\
223.9 & 222.5 & 219.5 & 221.2 & --- & Cl-P-Cl bending \\
200.6 & 202.2 & 195.2 & 200.9 & --- & Cl-P-Cl bending \\
187.7 & 195.0 & 186.4 & 185.2 & --- & Cl-P-Cl bending \\
181.7 & 181.3 & 175.2 & 173.3 & --- & Cl-P-Cl bending \\
160.4 & 163.7 & 158.7 & 158.9 & --- & Cl-P bending \\
152.8 & 159.1 & 151.7 & 148.4 & --- & Cl-P-Cl bending \\
144.2 & 144.4 & 135.6 & 144.0 & --- & Cl-P-Cl bending \\
119.2 & 122.1 & 111.4 & 113.7 & --- & Cl-P-Cl bending \\
69.8 & 74.1 & 55.0 & 76.2 & --- & Cl-P-Cl bending \\
58.3 & 51.7 & 41.9 & 43.7 & --- & Cl-P-Cl bending \\
36.2 & 37.3 & 38.4 & 38.0 & --- & Ring bending \\
34.9 & 36.0 & 27.5 & 29.9 & --- & Cl-P-Cl bending \\
28.6 & 29.3 & 17.4 & 24.0 & --- & Cl-P-Cl bending \\
18.8() & 21.4 & 16.3 & 19.6 & --- & Ring bending \\
\hline & & & & &
\end{tabular}

Thermodynamic parameters: Table- 5 shows the total electronic and zero-point energies (ZPE) and other thermodynamic parameters of the 1,3,3,5,5-pentachloro-1-mono-(2amidopyridine)cyclo triphosphazene and its tautomers structures in the GSs and TSs. Results show that the energies in the GS increased in the sequence of GS4 > GS3 > GS1 > GS2, while the TS energies are TS2 > TS3 > TS1.

\section{TABLE-5}

ENERGIES OF THE 1,3,3,5,5-PENTACHLORO-1-MONO(2-AMIDOPYRIDINE)CYCLOTRIPHOSPHAZENE AND ITS TAUTOMERS STRUCTURES

\begin{tabular}{lcccc}
\hline & ZPE & E & G & H \\
\hline GS1 & 0.125081 & -3792.836517 & -3792.762872 & -3792.691442 \\
TS1 & 0.119373 & -3792.780663 & -3792.713116 & -3792.641465 \\
GS2 & 0.124646 & -3792.841350 & -3792.767889 & -3792.696807 \\
TS2 & 0.118681 & -3792.767747 & -3792.700308 & -3792.629310 \\
GS3 & 0.123077 & -3792.805257 & -3792.735165 & -3792.661800 \\
TS3 & 0.118742 & -3792.771977 & -3792.704176 & -3792.633505 \\
GS4 & 0.123080 & -3792.801657 & -3792.730731 & -3792.658220 \\
\hline
\end{tabular}

LUMO-HOMO energies: Fig. 3 shows the distribution of electron density on HOMO and LUMO orbitals and their energies.

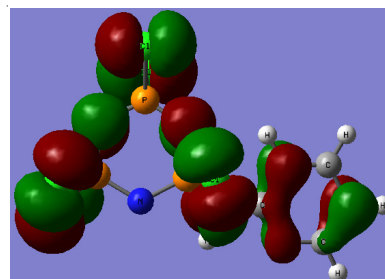

$\mathrm{HOMO}=-892.66 \mathrm{~kJ} / \mathrm{mol}$

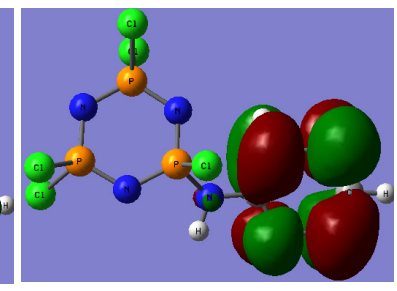

$\mathrm{LUMO}=-540.85 \mathrm{~kJ} / \mathrm{mol}$
Fig. 3. HOMO and LUMO orbitals of 1,3,3,5,5-pentachloro-1-mono-(2amidopyridine)cyclo triphosphazene

\section{REFERENCES}

1. Albright and Wilson Ltd., GB Patent 1016642 (1966).

2. Albright and Wilson Ltd., GB Patent 1017375 (1966).

3. V. Chandrasekhar and K.R.J. Thomas, Struct. Bonding, 81, 41 (1993).

4. B. Zanin, J.P. Faucher and J.F. Labarre, Inorg. Chim. Acta, 172, 147 (1990).

5. J.P. Bonnet and J.F. Labarre, Inorg. Chim. Acta, 149, 187 (1988).

6. H. Ibisoglu, Heterocycles, 71, 2173 (2007).

7. G. Yenilmez Ciftçi, E. Tanriverdi and Y. Zorlu, Heterocycles, 75, 635 (2008).

8. R. Andrews, IRCS Med. Sci., 7, 285 (1979).

9. G. Guerch, J.F. Labarre, R. Lahana, R. Roques and F. Sournies, J. Mol. Struct., 99, 275 (1983)

10. J. Liebig, Ann. Chem., 11, 139 (1834).

11. J.H. Gladstone and J.D. Holmes, J. Chem. Soc., 17, 225 (1864).

12. C.W. Allen, Chem. Rev., 91, 119 (1991).

13. R.N. Das, R.A. Shaw, B.C. Smith and M. Woods, J. Chem. Soc., Dalton Trans., 709 (1973).

14. D.J. Lingley, R.A. Shaw, M. Woods and S.S. Krishnamurthy, Phosphorus Sulfur, 4, 379 (1978).

15. S. Das, R. Keat, R.A. Shaw and B.C. Smith, J. Chem. Soc., 5032 (1965).

16. N.V. Mani and A.J. Wagner, Acta Crystallogr. B, 27, 51 (1971).

17. M.J. Begley, D.B. Sowerby and T.T. Bamgboye, J. Chem. Soc., Dalton Trans., 1401 (1979).

18. W. Polder and A.J. Wagner, Cryst. Struct. Commun., 5, 253 (1976).

19. S. Ganapathiappan and S.S. Krishnamurthy, J. Chem. Soc., Dalton Trans., 585 (1987).

20. V.B. Desai, R.A. Shaw and B.C. Smith, J. Chem. Soc. A, 2023 (1970). 21. H. Lederle, G. Ottman and E. Kober, Znorg. Chem., 5, 1818 (1966).

22. D.D. Perrin and W.L.F. Armagedo, Purification of Laboratory Chemicals, Perjamon Press, Oxford, edn. 3 (1988).

23. S.A. Ahmed, R.A. Haque, Z.H. Zetty, H.-K. Fun and W.-S. Loh, Acta Cryst., E68, o306 (2012).

24. M.J. Frisch, G.W. Trucks, H.B. Schlegel, G.E. Scuseria, M.A. Robb, J.R. Cheeseman, J.A. Montgomery, Jr., T. Vreven, K.N. Kudin, J.C. Burant, J.M. Millam, S.S. Iyengar, J. Tomasi, V. Barone, B. Mennucci, M. Cossi, G. Scalmani, N. Rega, G.A. Petersson, H. Nakatsuji, M. Hada, M. Ehara, K. Toyota, R. Fukuda, J. Hasegawa, M. Ishida, T. Nakajima, Y. Honda, O. Kitao, H. Nakai, M. Klene, X. Li, J.E. Knox, H.P. Hratchian, J.B. Cross, V. Bakken, C. Adamo, J. Jaramillo, R. Gomperts, R.E. Stratmann, O. Yazyev, A.J. Austin, R. Cammi, C. Pomelli, J.W. Ochterski, P.Y. Ayala, K. Morokuma, G.A. Voth, P. Salvador, J.J. Dannenberg, V.G. Zakrzewski, S. Dapprich, A.D. Daniels, M.C. Strain, O. Farkas, D.K. Malick, A.D. Rabuck, K. Raghavachari, J.B. Foresman, J.V. Ortiz, Q. Cui, A.G. Baboul, S. Clifford, J. Cioslowski, B.B. Stefanov, G. Liu, A. Liashenko, P. Piskorz, I. Komaromi, R.L. Martin, D.J. Fox, T. Keith, M.A. Al-Laham, C.Y. Peng, A. Nanayakkara, M. Challacombe, P.M.W. Gill, B. Johnson, W. Chen, M.W. Wong, C. Gonzalez and J.A. Pople, Gaussian 03, Revision C.02, Gaussian Inc., Wallingford CT (2004).

25. H. Koopman, F.J. Spruit, F. Van Deursen and J.Bakker, Rec. Trav. Chem., 84, 341 (1965)

26. U. Kropacheva and V.A. Parshina, Zhur. Obshchei. Khim., 35, 1988 (1965). 